\title{
Agroclimatic Environment of Various Zones of Potato in Assam, India
}

\author{
Bondita Goswami, Pranjal Dutta* and Rofiul Hussain \\ AICRPAM-NICRA, Department of Agrometeorology, Assam Agricultural University, \\ Jorhat-13, Assam, India \\ *Corresponding author
}

\section{A B S T R A C T}

\section{Keywords}

Agroclimatic zone,

Potato,

Environment

Article Info

Accepted:

18 August 2018

Available Online:

10 September 2018
Potato is one of the most important and widely cultivated vegetable crops of Assam and ranks fourth in terms of acreage under individual crop in the state. The present study features the agroclimatic-environment of potato zones of Assam developed on the basis of cumulative total frequency of area and productivity of potato. Data have been analysed since 1991-92 to 2015-16 in blocks of five years. Six potato zones were developed and analyzed for Assam. The analysis shows that zone-5 comprising of five districts has an average area and production of 1091.6 ha and 8220.1tonnes, respectively. The highest increase in area $(61 \%)$ and production $(64 \%)$ was recorded in the aforesaid zone. Area, production and productivity of potato in all the zones showed variation (i.e. increase or decrease) from 1991-92 to 2015-16. Zone wise highest contribution to area was found in zone 1 except for C (2001-02 to 06) and D (2006-07 to 11) block years. Similar trend was observed in production of potato apart from $\mathrm{D}$ block year.

\section{Introduction}

Potato (Solanum tuberosum) is an important food crop of the world which ranks fourth in production after cereals, cultivated worldwide for its tubers (FAO, 2010; Rhodes, 1982). In India, potato is grown in all the states producing 25 million tonnes from total area of 1.4 million ha. Among the northeastern states of India, Assam is the leading state with respect to acreage and production of potato and ranks fourth in terms of acreage under individual crop in the state. As per the latest available data, the state produced 677.3 thousand tones of potatoes from the area of 80.5 thousand ha (Anonymous, 2002). The productivity of potato in Assam, however, is as low as $7.57 \mathrm{t} \mathrm{ha}^{-1}$ (Gupta et al., 2009) which is far below than the national average of $19 \mathrm{t} \mathrm{ha}^{-1}$ and is quite disappointing though the state is having good potential in all aspects such as agroclimatic condition which varies from tropical type to temperate type and light texture soil with good aeration status. Further, Assam is a deficit state in terms of potato production which could be comprehended from the fact that every year a sizeable amount of potato comes to the state from the other parts of the country. Potato is a weather sensitive crop whose growth and production is influenced by climate and several other factors like use of improved varieties, good quality seed, planting time, nutrition and irrigation, incidence of pest and 
diseases and weeds. Among these factors, planting time plays a very important role in potato production as manipulation of light and temperature can be done to a certain extent by altering planting time. For best yields, potato crop needs long day conditions during growth and short day conditions during tuberization (Chadha, 2009). The main climatic factors controlling tuber formation are night temperature and day length (Cutter, 1992; Struik and Ewing, 1995). The climate and other natural resources of varied degree have undergone changes in different parts of the state.

These changes have occurred due to over exploitation under rice-potato cropping system and so it becomes essential to assess the magnitude of changes in various climatic parameters and other natural resources, which are likely to cause harmful effects on the productivity of the crops. The magnitude in changes over the past several years can be used for sustaining agricultural production in the state. Hence, there is need for characterization of agroclimatic environments for a particular crop to sustain long-term productivity.

The main objectives for agro climatic characterization is to analyze the productivity of potato in different agroclimatic zones of Assam.

\section{Materials and Methods}

The average data on area and productivity of Potato for different districts of Assam were used for zoning the state. The range was calculated with the help of cumulative total method (less than type).

The cumulative frequency of a given class interval thus represent the total of all the previous class frequencies including the class against which it is written (Sancheti and
Kapoor, 1986; Goswami et al., 2003). District-wise average area and productivity data (From 1991-92 to 2015-16) were arranged in ascending order and the cumulative totals were obtained to explain three categories using the following formula:

$\begin{array}{ll}\mathrm{CT} / 3=\mathrm{X} & <\mathrm{X}=\text { Low } \\ \mathrm{Z} \times 2=\mathrm{Y} & \mathrm{X}-\mathrm{Y}=\text { Medium } \\ & >\mathrm{Y}=\text { High }\end{array}$

Where CT is cumulative total, Values less than $\mathrm{X}$ were categorized as low, values less than $\mathrm{Y}$ categorized as medium and values higher than $\mathrm{Y}$ were categorized as high.

\section{Area (ha)}

Low (L) $[<29501.20]$

Medium (M) [29501.20-59002.39]

High $(\mathrm{H})$ [>59002.39]

\section{Productivity (t/ha)}

Low (L) $[<62.95]$

Medium (M) [62.95-125.91]

$\operatorname{High}(\mathrm{H})[>125.91]$

HH: High area, high productivity

HM: High area, medium productivity

MH: Medium area, high productivity

MM: Medium area, medium productivity

LM: Low area, medium productivity

LL: Low area, low productivity

On the basis of these cumulative totals, the districts were divided into different zones. The six zones of potato on the basis of area and productivity were obtained as mentioned above.

The long term rabi season rainfall of various districts of Assam were collected and analysed. The relevant information's on soil textural classification of the state were also collected. 


\section{Results and Discussion}

The state has been divided into six agroclimatic environment of various zones of potato based on area and productivity (Table $1)$.

\section{Zone-1(HH)}

Zone -1 of potato comprises of districts viz. Barpeta and Nagaon and has an average area and productivity of 7190.2 ha and $8.6 \mathrm{t} / \mathrm{ha}$, respectively. Rainfall of this zone during its crop growing period is $49.17 \mathrm{~mm}$.

\section{Zone-2 (HM)}

It encompasses Darrang and Sonitpur with an average area of 6232.5 ha and average productivity of $7.1 \mathrm{t} / \mathrm{ha}$. Rainfall throughout its period is $51.56 \mathrm{~mm}$.

Zone-3 (MH)

It includes Kamrup(R) and Dhubri districts having an average area and productivity of 5127.2 ha and 8.8 t/ha, respectively.

$33.61 \mathrm{~mm}$ of rainfall is received during its growing period.

Zone-4 (MM)

It comprises Nalbari with average area of 3536.5 ha and average productivity of 7.6 $\mathrm{t} / \mathrm{ha}$. Rainfall amount of $75.59 \mathrm{~mm}$ is received during its crop growing period.

Zone -5 (LM)

This zone consists of districts such as Sibsagar, Goalpara, Golaghat, Dima Hasao, Kamrup (M) with a average area and productivity of 1091.6 ha and $7.5 \mathrm{t} / \mathrm{ha}$, respectively. $70.62 \mathrm{~mm}$ of rainfall is received during its crop growth period.

Zone-6 (LL)
Hailakandi, Morigaon, Cachar, Karimganj, Tinsukia, Jorhat falls under this zone. The average area and productivity of this zone are $1756.2 \mathrm{ha}$ and $5.2 \mathrm{t} / \mathrm{ha}$, respectively. Maximum amount of rainfall i.e. $97.20 \mathrm{~mm}$ is received here during the potato growing period.

Assam has a wide range of soil texture which are rich in nitrogen and organic matter content. Maximum districts of Assam have alluvial soil and are highly fertile for raising varieties of crops round the year. Lateritic soils are confined to Dima Hasao district while red loamy soils are generally found in Karimganj.

Percent increase or decrease in area, production and productivity under potato zone in Assam

Area under potato increased in almost all the zones except in zone 1 and 2 (Table 2). The percent increased in area and production was highest in zone 5 i.e. $61 \%$ and $64 \%$, respectively while decreased in area and production was found in zone 3 and zone 4 , respectively (Table 3 and 4).

Likewise, percent increase in productivity was found in almost all the zones except in zone 4 (Table 5). Highest percent increase was found in zone $3(24 \%)$; on the contrary, lowest percent decrease in productivity was found in zone $4(-27 \%)$.

Zone wise contribution to area and production under potato in Assam

Zone wise contribution to area under potato in Assam increased in almost all the ones since last 25 years (Table 6). Majority of highest contribution was made from zone 1 except for $\mathrm{C}$ and D block years. Similar trend was observed in production of potato apart from $\mathrm{D}$ block year (Table 7). 
Table.1 Agro-climatic environment of various production zones of potato

\begin{tabular}{|c|l|c|c|c|l|}
\hline $\begin{array}{c}\text { SL } \\
\text { No. }\end{array}$ & Zone & $\begin{array}{c}\text { Rainfall } \\
\text { during its crop } \\
\text { growing } \\
\text { period(mm) }\end{array}$ & Soil texture & $\begin{array}{c}\text { Category } \\
\text { of Zone }\end{array}$ & \multicolumn{1}{|c|}{ Districts } \\
\hline $\mathbf{1}$ & Zone-1 & 49.17 & Alluvial soil & HH & Barpeta, Nagaon \\
\hline $\mathbf{2}$ & Zone-2 & 51.56 & Alluvial soil & HM & Darrang, Sonitpur \\
\hline $\mathbf{3}$ & Zone-3 & 33.61 & Alluvial soil, & MH & Kamrup(R), Dhubri \\
\hline $\mathbf{4}$ & Zone-4 & 75.59 & Alluvial soil & MM & Nalbari \\
\hline $\mathbf{5}$ & Zone-5 & 70.62 & $\begin{array}{c}\text { Alluvial soil, } \\
\text { Lateritic soil }\end{array}$ & LM & $\begin{array}{l}\text { Sibsagar, Goalpara, Golaghat, } \\
\text { Dima Hasao, Kamrup(M) }\end{array}$ \\
\hline $\mathbf{6}$ & Zone-6 & 97.20 & $\begin{array}{c}\text { Alluvial soil, } \\
\text { Red loamy } \\
\text { soil }\end{array}$ & LL & $\begin{array}{l}\text { Hailakandi, Morigaon, } \\
\text { Cachar, Karimganj, Tinsukia, } \\
\text { Jorhat }\end{array}$ \\
\hline & & & & & \\
\hline
\end{tabular}

Table.2 Zone-wise average area, production and productivity of Potato in Assam

\begin{tabular}{|c|c|c|c|}
\hline Zone & Area(ha) & Production(t) & Productivity(t/ha) \\
\hline $\mathbf{1}$ & 7190.2 & 63841.9 & 8.6 \\
\hline $\mathbf{2}$ & 6232.5 & 45231.9 & 7.1 \\
\hline $\mathbf{3}$ & 5127.2 & 44721.6 & 8.8 \\
\hline $\mathbf{4}$ & 3536.5 & 26918.1 & 7.6 \\
\hline $\mathbf{5}$ & 1091.6 & 8220.1 & 7.5 \\
\hline $\mathbf{6}$ & 1756.2 & 9616.3 & 5.2 \\
\hline
\end{tabular}

Table.3 Area (ha) of potato in different zones of Assam

\begin{tabular}{|c|c|c|c|c|c|c|}
\hline Zone & A & B & C & D & E & 100(E-A)/A(\% increase or decrease) \\
\hline $\mathbf{1}$ & 7736.6 & 8254.9 & 7000.5 & 5842.7 & 7047.3 & $\mathbf{- 8 . 9 1}$ \\
\hline $\mathbf{2}$ & 4837.2 & 6191.1 & 7092.4 & 6231.8 & 6669.0 & $\mathbf{3 7 . 8 7}$ \\
\hline $\mathbf{3}$ & 6040.8 & 6846.4 & 5359.5 & 3759.7 & 3832.9 & $\mathbf{- 3 6 . 5 5}$ \\
\hline $\mathbf{4}$ & 3840.6 & 3974.0 & 3620.2 & 2044.6 & 3974.4 & $\mathbf{3 . 4 8}$ \\
\hline $\mathbf{5}$ & 947.5 & 952.6 & 830.4 & 1256.8 & 1525.6 & $\mathbf{6 1 . 0 1}$ \\
\hline $\mathbf{6}$ & 1608.9 & 1876.1 & 1616.4 & 1597.2 & 1972.3 & $\mathbf{2 2 . 5 9}$ \\
\hline A- Represents average of five year block(1991-91 to 96) \\
\hline \multicolumn{3}{|l|}{ B- Represents average of five year block(1996-97 to 01) } \\
\hline \multicolumn{2}{|l|}{ C- Represents average of five year block(2001-02 to 06) } \\
\hline \multicolumn{3}{|l|}{ E- Represents average of five year block(2006-07 to 11) } \\
\hline
\end{tabular}


Table.4 Production ( $\mathrm{t}$ ) of Potato in different zones of Assam

\begin{tabular}{|c|c|c|c|c|c|c|}
\hline Zone & A & B & C & D & E & 100(E-A)/A (\% increase or decrease) \\
\hline $\mathbf{1}$ & 65430.2 & 94364.7 & 60138.6 & 41338.2 & 60911.9 & $\mathbf{- 6 . 9}$ \\
\hline $\mathbf{2}$ & 31102.1 & 46841.6 & 51892.6 & 45323.2 & 49112.4 & $\mathbf{5 7 . 9}$ \\
\hline $\mathbf{3}$ & 46591.7 & 63096.3 & 41573.4 & 37182.0 & 36493.9 & $\mathbf{- 2 1 . 7}$ \\
\hline $\mathbf{4}$ & 32827.2 & 35012.0 & 24959.2 & 15201.0 & 24929.4 & $\mathbf{- 2 4 . 1}$ \\
\hline $\mathbf{5}$ & 6958.2 & 7330.2 & 6000.2 & 9800.8 & 11377.9 & $\mathbf{6 3 . 5}$ \\
\hline $\mathbf{6}$ & 8505.5 & 11634.9 & 8663.4 & 7551.1 & 10804.2 & $\mathbf{2 7 . 0}$ \\
\hline A- Represents average of five year block(1991-91 to 96) & \\
\hline B- Represents average of five year block(1996-97 to 01) & \\
\hline \multicolumn{2}{l}{ C- Represents average of five year block(2001-02 to 06) } \\
\hline D- Represents average of five year block(2006-07 to 11) \\
\hline E- Represents average of five year block(2011-12 to 16) \\
\hline
\end{tabular}

Table.5 Productivity (t/ha) of Potato in different zones of Assam

\begin{tabular}{|c|c|c|c|c|c|c|}
\hline Zone & A & B & C & D & E & 100(E-A)/A (\% increase or decrease) \\
\hline $\mathbf{1}$ & 7.9 & 11.0 & 8.5 & 7.0 & 8.6 & $\mathbf{8 . 5}$ \\
\hline $\mathbf{2}$ & 6.2 & 7.5 & 7.2 & 7.1 & 7.4 & $\mathbf{1 8 . 4}$ \\
\hline $\mathbf{3}$ & 7.6 & 9.3 & 7.6 & 10.0 & 9.5 & $\mathbf{2 4 . 2}$ \\
\hline $\mathbf{4}$ & 8.6 & 8.8 & 6.8 & 7.5 & 6.3 & $\mathbf{- 2 6 . 7}$ \\
\hline $\mathbf{5}$ & 7.4 & 7.9 & 6.9 & 7.5 & 7.5 & $\mathbf{1 . 7}$ \\
\hline $\mathbf{6}$ & 4.9 & 5.5 & 5.1 & 4.7 & 5.5 & $\mathbf{1 3 . 0}$ \\
\hline
\end{tabular}

A- Represents average of five year block(1991-91 to 96)

B- Represents average of five year block(1996-97 to 01)

C- Represents average of five year block(2001-02 to 06)

D- Represents average of five year block(2006-07 to 11)

E- Represents average of five year block(2011-12 to 16)

Table.6 Zone wise contribution (\%) to area under potato in Assam

\begin{tabular}{|c|c|c|c|c|c|}
\hline Zone & A & B & C & D & E \\
\hline $\mathbf{1}$ & 11.5 & 10.8 & 8.1 & 7.3 & 7.1 \\
\hline $\mathbf{2}$ & 7.2 & 8.1 & 8.2 & 7.8 & 6.7 \\
\hline $\mathbf{3}$ & 9.0 & 8.9 & 6.2 & 4.7 & 3.8 \\
\hline $\mathbf{4}$ & 5.7 & 5.2 & 4.2 & 2.6 & 4.0 \\
\hline $\mathbf{5}$ & 1.4 & 1.2 & 1.0 & 1.6 & 1.5 \\
\hline $\mathbf{6}$ & 2.4 & 2.5 & 1.9 & 2.0 & 2.0 \\
\hline
\end{tabular}

A- Represents average of five year block(1991-91 to 96) State average $=67109.4$

B- Represents average of five year block(1996-97 to 01) State average $=76558$

C- Represents average of five year block(2001-02 to 06) State average $=86696.8$

D- Represents average of five year block(2006-07 to 11) State average $=79775.6$

E- Represents average of five year block(2011-12 to 16) State average $=99908.2$ 
Table.7 Zonewise contribution (\%) to production under potato in Assam

\begin{tabular}{|c|c|c|c|c|c|}
\hline Zone & A & B & C & D & E \\
\hline $\mathbf{1}$ & 13.4 & 14.6 & 10.3 & 7.4 & 8.5 \\
\hline $\mathbf{2}$ & 6.4 & 7.2 & 8.9 & 8.1 & 6.9 \\
\hline $\mathbf{3}$ & 9.6 & 9.8 & 7.2 & 6.6 & 5.1 \\
\hline $\mathbf{4}$ & 6.7 & 5.4 & 4.3 & 2.7 & 3.5 \\
\hline $\mathbf{5}$ & 1.4 & 1.1 & 1.0 & 1.8 & 1.6 \\
\hline $\mathbf{6}$ & 1.7 & 1.8 & 1.5 & 1.3 & 1.5 \\
\hline
\end{tabular}

A- Represents average of five year block(1991-91 to 96) State average $=487812.4$

B- Represents average of five year block(1996-97 to 01) State average $=646723.6$

C- Represents average of five year block(2001-02 to 06) State average $=581386.6$

D- Represents average of five year block(2006-07 to 11) State average $=559781.8$

E- Represents average of five year block(2011-12 to 16) State average $=713828.6$

The agro-environment of potato zones of Assam were developed on the basis of cumulative total frequency of area and productivity of potato. Data were analysed since $1991-92$ to $2015-16$ in blocks of five years. Six potato zones were developed and analysed for Assam. The analysis shows that zone-5 comprising of five districts has an average area and production of 1091.6 ha and 8220.1 tonnes, respectively. The highest increase in area $(61 \%)$ and production $(64 \%)$ was recorded in the aforesaid zone. Area, production and productivity of potato in all the zones showed variation (i.e. increase or decrease) from 1991-92 to 2015-16. Zone wise highest contribution to area was found in zone 1 except for $\mathrm{C}$ and $\mathrm{D}$ block years. Similar trend was observed in production of potato apart from D block year.

\section{References}

Anonymous (2002). Potato cultivation in North Eastern India, Extension Bulletin N0. 34 (E), Central Potato Research Institute, Shimla (H.P) INDIA.
Chadha KL. Handbook of Horticulture, ICAR, New Delhi, 2009.

Cutter EG. Structure and development of the potato plant. In P. M. Harris ed., The Potato Crop. Chapman \& Hall, London, 1992, 65-161.

FAO (Food and Agricultural Organization). Traditional Food plants. A resource book for promoting the exploitation and consumption of food plants in arid, semi-arid and sub-humid lands of Eastern Africa. FAO Food Nutr. 2010; 42:458-466.

Goswami, B., Mahi, G.S., Hundal, S.S. and Saikia, U.S. (2003). Agroclimatic environment of various zones of Wheat in Punjab. Ann. agric. Res New Series Vol., 24(3): 481-486.

Gupta, V.K; Joseph, T.A and Srivasta, A.K (2009) Potato varieties popular in the North -Eastern Region. Souvenir of Golden Jubilee Celebration on Potato in North-East, Centarl Potato Research Station, Shillonh, Meghalaya pp: 3642.

Rhodes RE. The Incredible Potato. Natl. Geogr. 1982; 161:668-694.

Sancheti, D.C. and Kapoor, V.K. (1986). Statistics, theory, method and application, New Delhi, Sultan Chand and Sons, pp.297.

Struik PC, Ewing EE. Crop physiology of potato (Solanum tuberosum): responses to photoperiod and temperature relevant to crop modelling, 1995.

\section{How to cite this article:}

Bondita Goswami, Pranjal Dutta and Rofiul Hussain. 2018. Agroclimatic Environment of Various Zones of Potato in Assam, India. Int.J.Curr.Microbiol.App.Sci. 7(09): 2620-2625. doi: https://doi.org/10.20546/ijcmas.2018.709.326 